\title{
Divergência genética em feijoeiro em condições de inverno tropical(1)
}

\author{
Maria Amélia Gava Ferrão(2), Clibas Vieira(3) ${ }^{(3)}{ }^{(2 m e ~ D a m i a ̃ o ~}$ Cruz $^{(4)}$ e Antônio Américo Cardoso ${ }^{(3)}$
}

Resumo - O objetivo deste trabalho foi avaliar a divergência genética de genitores de feijão tolerantes e não-tolerantes às condições de inverno e de suas combinações híbridas. A distância generalizada de Mahalanobis, o método de agrupamento de otimização de Tocher e a técnica de variáveis canônicas foram os procedimentos multivariados utilizados. Nos cruzamentos, utilizaram-se cultivares de feijão que se adaptam bem às condições de inverno, ou seja: Vermelho 2157, Ouro Negro, Antióquia 8 e Ricopardo 896, e as cultivares comerciais não-tolerantes, EMCAPA 404 - Serrano, Carioca e EMCAPA 405 - Goytacazes. Os genitores e as combinações híbridas nas gerações $F_{1}$, $F_{2}$ e $F_{3}$ foram avaliados em Coimbra, Minas Gerais, em quatro ensaios, nos anos de 1995 e 1996. A divergência genética dos germoplasmas foi influenciada pela temperatura e pelo estádio de melhoramento. As cultivares mais dissimilares foram Antióquia 8 e EMCAPA 404 - Serrano, e as mais similares foram, Ouro Negro e Ricopardo 896. O rendimento de grãos e o número de vagens por parcela apresentaram-se como as características de menor importância relativa no estudo da divergência genética. No entanto, como apresentaram baixa correlação genotípica com as demais características e eram as de maior importância no processo produtivo, não devem ser descartadas.

Termos para indexação: Phaseolus vulgaris, híbridos, genitores, variação genética, análise multivariada.

\section{Genetic divergency on Common bean under tropical winter conditions}

\begin{abstract}
This work aimed to evaluate the genetic divergency among tolerants and non tolerants parents to cold and their hybrid combinations. The generalized distance of Mahalanobis, the method of cluster analysis proposed by Tocher and the canonical variability technic were the multivaried procedures used. Common bean cultivars of two different groups were used in the crosses, being Vermelho 2157, Ouro Negro, Antióquia 8 and Ricopardo 896 the cultivars tolerant to cold, and the commercial cultivars EMCAPA 404 - Serrano, Carioca and EMCAPA 405 - Goytacazes the non tolerant ones. The parents and the hybrid combinations in the $\mathrm{F}_{1}, \mathrm{~F}_{2}$ and $\mathrm{F}_{3}$ generations were evaluated in Coimbra, Minas Gerais on four experiments, in 1995 and 1996. The genetic divergency among the genetic resources evaluated were influenced by temperature and advancement of the generations. The most dissimilar cultivars were Antióquia 8 and EMCAPA 404 - Serrano and Ouro Negro and Ricopardo 896 were the most similar cultivars. Grain yield and number of pods per plot were the less important characteristics influencing on genetic divergency. However, as they showed low genotypic correlation with the other characteristics and were of the greatest importance on yield, they can not be despised.
\end{abstract}

Index terms: Phaseolus vulgaris, hybrids, parents, genetic variation, multivariate analysis.

(1) Aceito para publicação em 19 de junho 2001. Extraído da tese de doutorado apresentada pelo primeiro autor à Universidade Federal de Viçosa (UFV), Viçosa, MG.

${ }^{(2)}$ Instituto Capixaba de Pesquisa, Assistência Técnica e Extensão Rural, Centro Regional de Desenvolvimento Rural Centro-Serrano, BR 262, km 94, CEP 29375-000 Venda Nova do Imigrante, ES. E-mail: crdrcserrano@incaper.es.gov.br

${ }^{(3)}$ UFV, Dep. de Fitotecnia, CEP 36571-000 Viçosa, MG. E-mail: cbvieira@mail.ufv.br, aacardoso@mail.ufv.br

(4)UFV, Dep. de Biologia. E-mail: cdcruz@mail.ufv.br

\section{Introdução}

Os estudos a respeito de divergência genética apresentam grande relevância no melhoramento de plantas, por fornecerem parâmetros para identificação de progenitores que, quando cruzados, possibilitam o aparecimento de materiais superiores, além de facilitarem o conhecimento da base genética da população. Segundo Falconer (1981), a variabilida- 
de genética de uma população segregante depende da divergência genética entre os pais envolvidos nos cruzamentos.

Nesse contexto, a utilização da teoria de análise multivariada tem-se mostrado promissora, pois permite combinar todas as informações contidas na unidade experimental, de modo que as inferências sejam fundamentadas em um complexo de variáveis. Conforme Cruz \& Regazzi (1994), a análise multivariada é um processo alternativo para a avaliação do grau de similaridade genética entre tratamentos, cujo princípio consiste em resumir um grande número de características em outro menor, facilitando a análise dos dados. Permite, também, conhecer a similaridade entre os indivíduos, através de suas distâncias, ou através de sua dispersão gráfica no espaço bi ou tridimensional e avaliar a importância de cada variável para a variação total observada entre as unidades amostrais, possibilitando a eliminação das que pouco contribuem para a variação.

Muitos trabalhos em genética e melhoramento vegetal têm empregado técnicas multivariadas no estudo de divergência genética, como o de Davis (1975), em feijão; de Peter \& Ray (1976), em tomate; de Cruz (1990), em milho; de Soares (1990), em batata-baroa.

O objetivo deste trabalho foi avaliar a divergência genética entre genitores de feijão que se adaptam ou não às condições de inverno e suas combinações híbridas, com base em procedimentos multivariados.

\section{Material e Métodos}

Foram avaliadas sete cultivares de feijão e 12 combinações híbridas em diferentes gerações, no inverno de 1995 e 1996. Nos cruzamentos utilizaram-se cultivares de feijão pertencentes a dois grupos, sendo o grupo 1 formado pelas cultivares que se adaptam bem ao inverno (Vermelho 2157, Ouro Negro, Antióquia 8 e Ricopardo 896), selecionadas por Vieira et al. (1994), e o grupo 2, por cultivares comerciais (EMCAPA 404 - Serrano, Carioca e EMCAPA 405 - Goytacazes), que não são tolerantes ao inverno.

Foram conduzidos quatro ensaios, com os sete genitores e as 12 combinações híbridas entre os dois grupos, em Coimbra, MG, em campo experimental situado à altitude de aproximadamente $700 \mathrm{~m}$, conforme descrito a seguir: Ensaio 1 - $F_{1} / 95$ : geração $F_{1}$ e genitores - 1995; Ensaio 2 -
$\mathrm{F}_{2} / 95$ : geração $\mathrm{F}_{2}$ e genitores - 1995; Ensaio $3-\mathrm{F}_{2} / 96$ : geração $F_{2}$ e genitores - 1996; e Ensaio 4 - $F_{3} / 96$ : geração $\mathrm{F}_{3}$ e genitores -1996.

No ano de 1995, o plantio nos ensaios 1 e 2 foi realizado em 5/5/1995, e a colheita, entre 14/8/1995 e 25/8/1995. No ensaio 1, utilizaram-se três repetições e parcelas constituídas de uma linha de 1,0 m de comprimento; o ensaio 2 foi instalado com seis repetições e parcelas de duas linhas de 5,0 m de comprimento. Em 1996, os ensaios 3 e 4 foram instalados em 20/5/1996, com quatro repetições e parcelas constituídas de duas linhas de 5,0 m de comprimento. A colheita foi realizada entre 17/9/1996 e $7 / 10 / 1996$. Nos quatro ensaios utilizaram-se bordaduras externas, espaçamento entre linhas de $0,50 \mathrm{~m}$ e densidade de 10 plantas por metro após o desbaste. Na colheita, eliminou-se $0,25 \mathrm{~m}$ das extremidades de cada parcela.

Em todos os ensaios, utilizaram-se na adubação de plantio $600 \mathrm{~kg} / \mathrm{ha}$ da fórmula 4-14-8 e, em cobertura, $100 \mathrm{~kg} / \mathrm{ha}$ de sulfato de amônia, aplicados em cobertura 30 dias após o plantio. Os tratos culturais, a irrigação e o controle de pragas e doenças foram feitos de acordo com as necessidades da cultura.

Foram avaliadas as seguintes características: número de dias para emergência (EMERG), para florescimento (FLOR) e para colheita (MAT); número total de vagens/parcela, expresso em área de 4,5 m² (NVP); número de sementes/vagem (NSV), medida pela relação entre o total de sementes e o total de vagens da parcela; peso de 100 sementes, em g (PCS); e rendimento de grãos/ha (RGH), referente ao peso total da parcela expresso em $\mathrm{kg} / \mathrm{ha}$.

Preliminarmente, os dados de cada ensaio foram submetidos à análise de variância, a fim de avaliar a existência de variabilidade genética significativa entre tratamentos.

A divergência genética entre os tratamentos foi determinada pelas técnicas multivariadas que se baseiam na análise de agrupamento e de variáveis canônicas, apresentadas por Cruz \& Regazzi (1994). Na análise de agrupamento, utilizou-se a distância generalizada de Mahalanobis como medida de dissimilaridade, e, na delimitação dos grupos, a técnica de otimização, proposta por Tocher, citada por Rao (1952). Quanto à análise por variáveis canônicas, a divergência genética foi evidenciada pela dispersão dos escores em gráficos, com os eixos representados pelas primeiras variáveis canônicas. Realizou-se, também, o estudo da importância relativa das características na predição da divergência genética. Todas as análises foram feitas com o programa computacional GENES (Cruz, 1997). 


\section{Resultados e Discussão}

As temperaturas máximas, mínimas e médias foram distintas nos anos de 1995 e 1996 (Figura 1). No ano de 1995 o inverno foi menos frio e, em 1996, as temperaturas foram mais variáveis e mais baixas, principalmente no período do florescimento.

Houve variabilidade genética entre tratamentos $(\mathrm{P}<0,01)$ para a maioria das características, exceto RGH no ensaio 4, e coeficiente de variação ambiental oscilando de 1,324 a $15,834 \%$, o que caracteriza boa precisão experimental (Tabela 1).

A análise da diversidade genética entre os genitores, com base na distância generalizada de Mahalanobis, permite constatar que, no grupo 1, representado pelas cultivares que se adaptam bem às condições de inverno, a Ouro Negro e a Ricopardo 896, são as mais similares, e a cultivar Antióquia 8 é bastante divergente em relação às demais (Tabelas 2 e 3). O grupo 2, representado por cultivares

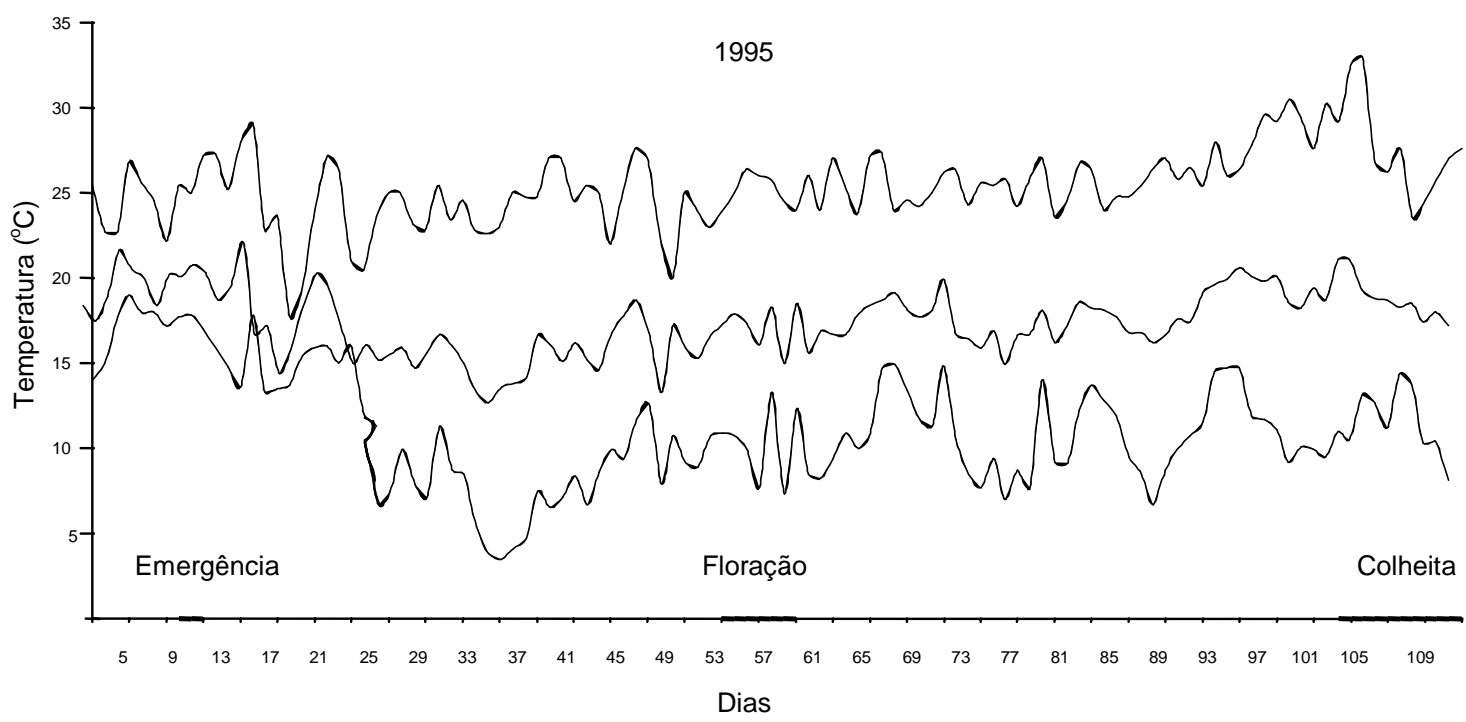

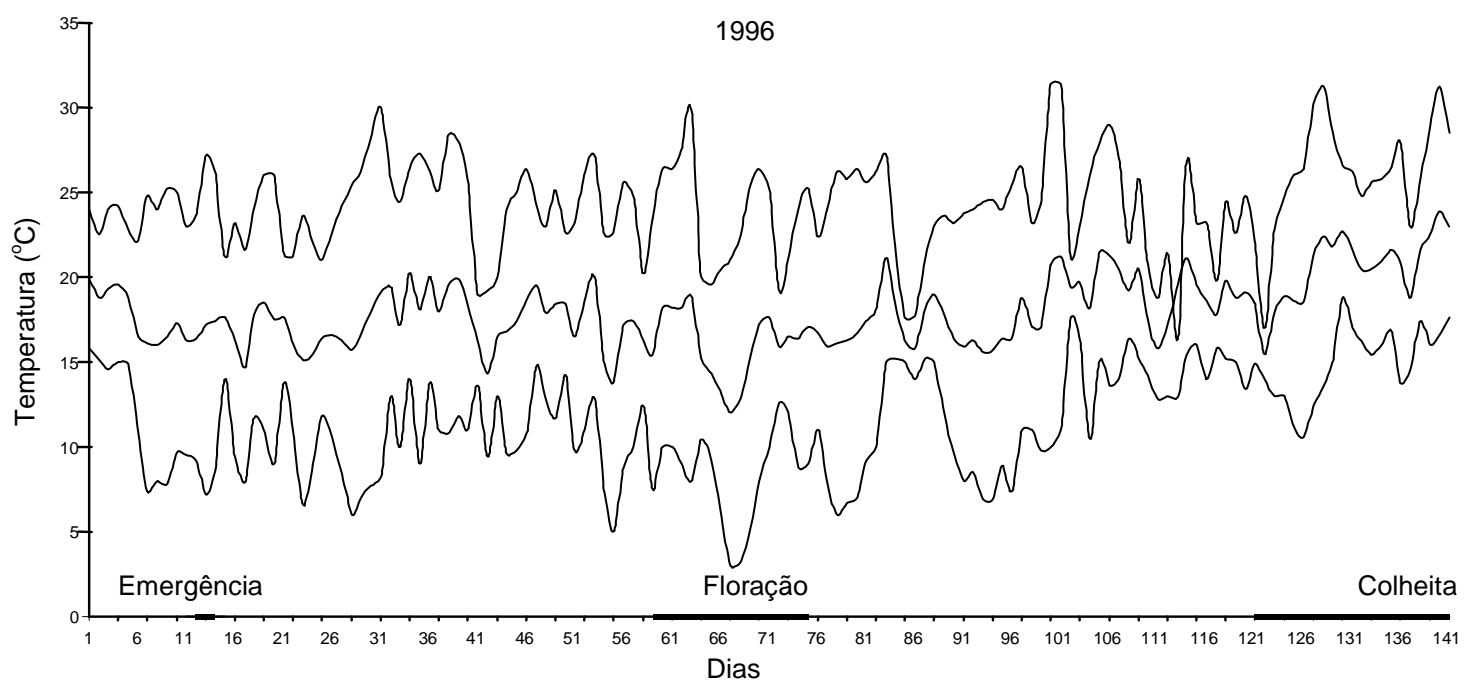

Figura 1. Temperaturas máximas, médias e mínimas vigentes durante o ciclo da cultura no ano de 1995 e 1996, em Coimbra, MG. 
comerciais, apresentam, de maneira geral, mesmo nível de similaridade (ou dissimilaridade), sendo mais próximos entre si, do que os genitores do grupo 1.

Houve grande divergência das combinações híbridas em relação à Antióquia 8. Considerando que genótipos com alta concentração de alelos dominantes, ao transmitir seus gametas, deixam descendência mais similares a si do que os de alta concentração de recessivo, constata-se que a Antióquia 8 deve apresentar formas alélicas complementares às dos demais genitores, as quais devem estar fixadas em alelos recessivos. Em estudos genéticos, procura-se basear a escolha de genitores também pela concentração de alelos favoráveis e pela complementação alélica, quando o programa de melhoramento baseiase na hibridação. Alelos favoráveis dominantes proporcionam maior quantidade de genótipos superiores em geração segregantes, permitindo identificar indivíduos superiores com menor tamanho populacional. O genitor Ricopardo 896, do grupo 1, ao contrário, parece que concentra maior proporção de alelos dominantes, dada a sua proximidade em relação à descendência.
Na comparação da divergência genética dos materiais genéticos nos diferentes ensaios, não se observou analogia direta entre os resultados dos ensaios conduzidos no mesmo ano, constituídos das gerações $F_{1}$ 's e $F_{2}$ 's no ano de 1995 , e das gerações $\mathrm{F}_{2}$ 's $\mathrm{e} \mathrm{F}_{3}$ 's, no ano de 1996 e dos mesmos materiais em anos diferentes, ou seja, os genitores e as gerações híbridas $\mathrm{F}_{2}$. De modo geral, tais resultados foram similares, em relação à divergência genética dos genitores, com variação na ordem de classificação deles, ressaltando-se que as combinações híbridas mais dissimilares envolveram o progenitor de número 15 (Antióquia 8), do grupo 1.

Em ambos os ensaios, houve a formação de apenas dois grupos, com a ressalva de que, como já anteriormente detectado na matriz de dissimilaridade, a cultivar 15 (Antióquia 8) apresentou-se como a mais divergente, ficando no grupo 2 (Tabela 4). Posteriormente, reagrupou-se o grupo 1, o qual foi composto de seis subgrupos, nos ensaios 1 e 3 , três, no ensaio 2 e, cinco, no ensaio 4. Nos subgrupos 1a e $1 \mathrm{~b}$, que reuniram o maior número de materiais, apareceram, em todos os ensaios, os genitores Ouro

Tabela 1. Análise de variância dos caracteres dias para emergência (EMERG), florescimento (FLOR), maturação (MAT), número de sementes/vagem (NSV), número de vagens/parcela (NVP), peso de 100 sementes (PCS) e rendimento de grãos/ha (RGH) referentes aos ensaios 1, 2, 3 e 4.

\begin{tabular}{|c|c|c|c|c|c|c|c|c|c|}
\hline \multirow[t]{2}{*}{ Ensaios $^{(1)}$} & \multirow{2}{*}{$\begin{array}{l}\text { Fonte de } \\
\text { variação }\end{array}$} & \multirow[t]{2}{*}{ GL } & \multicolumn{7}{|c|}{ Quadrados médios } \\
\hline & & & EMERG & FLOR & MAT & NSV & NVP & PCS & RGH \\
\hline \multirow[t]{5}{*}{1} & Blocos & 2 & 0,017 & 0,366 & 0,483 & 0,038 & $65.375,184$ & 3,254 & $533.157,062$ \\
\hline & Tratamento & 18 & $0,179 * *$ & $5,535 * *$ & $8,377 * *$ & $0,833 * *$ & $187.336,672 * *$ & $100,377 * *$ & $624.457,500$ ** \\
\hline & Resíduo & 36 & 0,036 & 1,609 & 1,343 & 0,164 & $50.427,089$ & 3,034 & $162.837,641$ \\
\hline & Média & & 7,090 & 47,684 & 96,877 & 3,960 & $1.418,190$ & 22,914 & $2.849,544$ \\
\hline & $\mathrm{CV}_{\mathrm{e}}(\%)$ & & 2,680 & 2,660 & 1,961 & 10,212 & 15,834 & 7,602 & 14,163 \\
\hline \multirow[t]{5}{*}{2} & Blocos & 5 & 0,535 & 4,599 & 16,501 & 0,193 & $30.818,163$ & 4,675 & $247.382,906$ \\
\hline & Tratamento & 18 & $1,350 * *$ & $14,966^{* *}$ & $26,789 * *$ & $0,927 * *$ & $151.694,555 * *$ & $151,791 * *$ & $639.136,000^{* *}$ \\
\hline & Resíduo & 90 & 0,194 & 0,732 & 4,635 & 0,128 & $10.359,907$ & 3,514 & $44.791,973$ \\
\hline & Média & & 7,149 & 47,772 & 99,298 & 3,828 & 995,370 & 26,246 & $1.833,607$ \\
\hline & $\mathrm{CV}_{\mathrm{e}}(\%)$ & & 6,166 & 1,791 & 2,168 & 9,370 & 10,230 & 7,143 & 11,542 \\
\hline \multirow[t]{5}{*}{3} & Blocos & 3 & 3,403 & 35,556 & 7,932 & 0,064 & $7.196,298$ & 3,302 & $84.009,608$ \\
\hline & Tratamento & 18 & $2,627 * *$ & $65,008 * *$ & $75,260 * *$ & $0,619 * *$ & $49.915,652 * *$ & $105,881 * *$ & $50.054,531^{\mathrm{ns}}$ \\
\hline & Resíduo & 54 & 0,191 & 4,603 & 2,388 & 0,122 & $10.020,266$ & 2,313 & $28.323,442$ \\
\hline & Média & & 10,947 & 64,644 & 127,645 & 3,478 & 828,539 & 25,358 & $1.460,788$ \\
\hline & $\mathrm{CV}_{\mathrm{e}}(\%)$ & & 3,987 & 3,319 & 1,212 & 10,049 & 12,082 & 5,998 & 11,521 \\
\hline \multirow[t]{5}{*}{4} & Blocos & 3 & 0,434 & 5,665 & 7,153 & 0,079 & $8.107,421$ & 2,319 & $22.855,353$ \\
\hline & Tratamento & 18 & $0,870 * *$ & $48,739 * *$ & $48,278 * *$ & $0,517 * *$ & $29.309,736^{* *}$ & $78,706^{* *}$ & $50.460,999 * *$ \\
\hline & Resíduo & 54 & 0,156 & 2,773 & 2,792 & 0,052 & $6.064,213$ & 1,2186 & $21.381,340$ \\
\hline & Média & & 10,355 & 52,697 & 126,224 & 3,428 & 852,750 & 24,107 & $1.377,469$ \\
\hline & $\mathrm{CV}_{\mathrm{e}}(\%)$ & & 3,819 & 3,160 & 1,324 & 6,683 & 9,132 & 4,704 & 10,615 \\
\hline
\end{tabular}

${ }^{(1)} 1-F_{1} / 1995$ : geração $F_{1}$ e genitores; $2-F_{2} / 1995$ : geração $F_{2}$ e genitores; $3-F_{2} / 1996$ : geração $F_{2}$ e genitores; $4-F_{3} / 1996$ : geração $F_{3}$ e genitores. ${ }^{\text {ns } N a ̃ o-~}$ significativo. **Significativo a $1 \%$ de probabilidade pelo teste $\mathrm{F}$. 


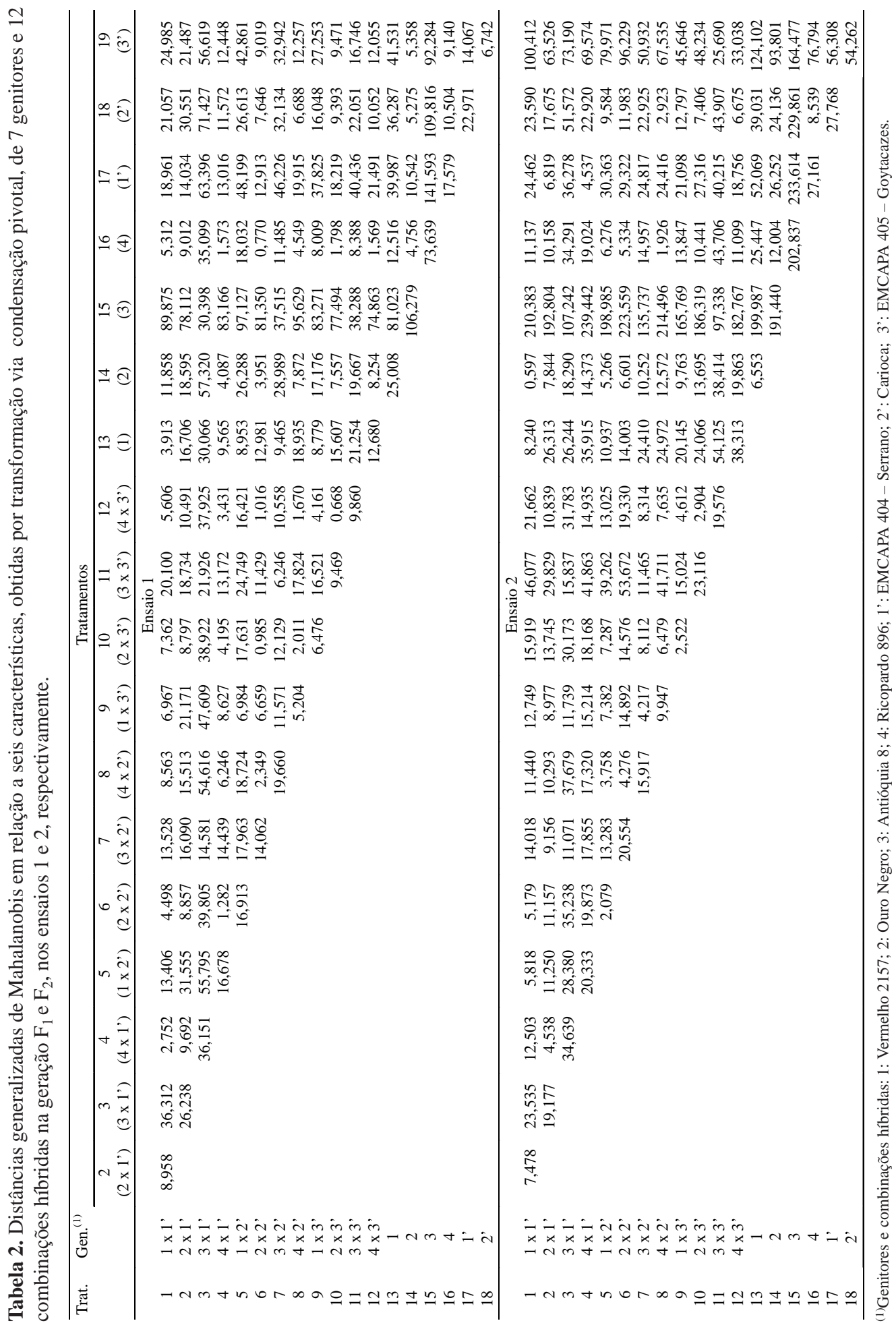




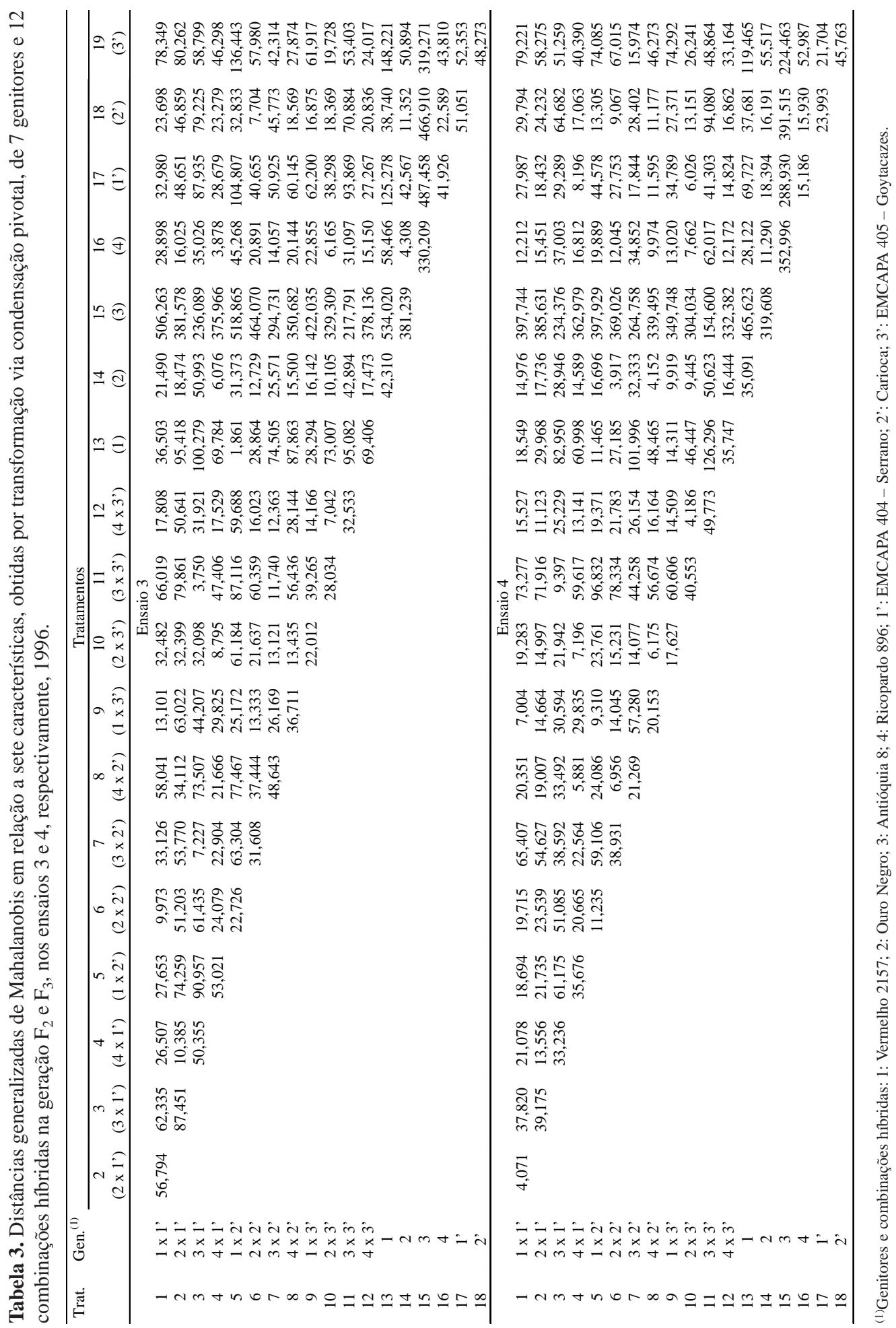


Negro e Ricopardo 896, do grupo adaptado ao inverno. As combinações híbridas mais dissimilares foram Antióquia 8 x EMCAPA 404 - Serrano (3 x 1'), Ouro Negro x EMCAPA 404 - Serrano ( 2 x 1') e Antióquia 8 x EMCAPA 405 - Goytacazes (3 $\left.\times 3^{\prime}\right)$.

O Ricopardo 896 (tratamento 16) passou suas características fenotípicas à descendência, o que indica sua concentração de alelos dominantes (Tabela 4). Seus híbridos obtidos com o cruzamento com EMCAPA 404 - Serrano (tratamento 4), Carioca (tratamento 8) e EMCAPA 405 - Goytacazes (tratamento 12) estiveram sempre no mesmo grupo, exceto no ensaio 3 , em que o híbrido 4 x 2' (tratamento 8) foi classificado no grupo 1c, e os demais, no 1 b. Estes resultados são ainda de maior importância, pois as informações são consistentes em relação às gerações $F_{1}, F_{2}$ e $F_{3}$, o que demonstra a potencialidade do genitor em programas de melhoramento. Outras similaridades entre genitor e descendência, nas várias gerações, são encontradas entre Vermelho 2157 e Vermelho 2157 x Carioca ou de Ouro Negro x Carioca.

A utilização das variáveis canônicas no estudo de divergência genética teve como propósito a identificação de genótipos similares em gráficos de dispersão bi ou tridimensional, possibilitando, assim, simplificar a interpretação dos resultados. A viabilidade de sua utilização está restrita à concentração da variabilidade disponível entre as primeiras variáveis, a qual é referenciada por muitos autores, citados por Cruz \& Regazzi (1994), como acima de $80 \%$. As estimativas dos autovalores associadas às variáveis canônicas $\left(\mathrm{VC}_{\mathrm{i}}\right)$, referentes aos ensaios 1 e 2, estão incluídas na Tabela 5, e as dos ensaios 3 e 4, na Tabela 6 . No ensaio 1, as duas primeiras variáveis canônicas acumularam próximo de $80 \%$ da variação total, e, nos demais ensaios, mais de $80 \%$, levando, assim, a se tomarem apenas as duas primeiras variáveis, em todos os quatro ensaios, no estudo gráfico de dispersão (Figura 2).

Em todos os ensaios, a cultivar Antióquia 8 mostrou-se como a mais divergente em relação aos outros materiais. Entre os genitores, os mais dissimilares foram Antióquia 8 e Vermelho 2157, no grupo 1, e EMCAPA 405 - Goytacazes, no grupo 2. As dispersões dos genitores e das populações $\mathrm{F}_{2}$, relativos aos ensaios 2 e 3, dos anos de 1995 e 1996, respectivamente, foram similares com a utilização das duas primeiras variáveis canônicas.

A cultivar Antióquia 8, identificada como a mais divergente, apresenta semente grande, fato importante quando se analisam a origem e a domesticação do feijoeiro. Segundo Gepts et al. (1986), existem duas áreas de domesticação do feijoeiro: uma, na América Central, que deu origem às cultivares com sementes pequenas, e duas, na América do Sul, sendo uma delas no sul dos Andes (Peru e Argentina), e a outra, no norte dos Andes (Colômbia), originando os materiais com sementes grandes e pequenas, respectivamente.

O genitor Antióquia 8 diferencia-se dos demais em razão de sua origem ser, provavelmente, a América do Sul, especialmente a região dos Andes (Peru

Tabela 4. Agrupamento de 7 genitores e 12 combinações híbridas de feijão, pelo método de Tocher, com base na distância generalizada de Mahalanobis, dos ensaios 1, 2, 3 e $4^{(1)}$.

\begin{tabular}{|c|c|c|c|c|c|}
\hline \multirow[t]{3}{*}{ Grupo } & \multirow[t]{3}{*}{ Subgrupo } & \multicolumn{2}{|c|}{1995} & \multicolumn{2}{|c|}{1996} \\
\hline & & Ensaio 1 & Ensaio 2 & Ensaio 3 & Ensaio 4 \\
\hline & & $\begin{array}{c}\text { Genitores e híbridos } \\
\mathrm{F}_{1} \\
\end{array}$ & $\begin{array}{c}\text { Genitores e gerações } \\
\mathrm{F}_{2} \\
\end{array}$ & $\begin{array}{c}\text { Genitores e gerações } \\
\mathrm{F}_{2} \\
\end{array}$ & $\begin{array}{c}\text { Genitores e gerações } \\
\mathrm{F}_{3} \\
\end{array}$ \\
\hline 1 & $\mathrm{a}$ & $\begin{array}{c}10,12,6,16,4,8,1, \\
9,14\end{array}$ & $\begin{array}{c}1,14,5,6,8,16,2,9 \\
10,7,12,18,4,17,13\end{array}$ & $5,13,6,9,1,18,14$ & $\begin{array}{c}6,14,8,10,16,4,18 \\
12,17\end{array}$ \\
\hline & b & 7,11 & 3,11 & $3,11,7,10,12,16,4$ & $1,2,9$ \\
\hline & $\mathrm{c}$ & 18,19 & 19 & 8 & 3,11 \\
\hline & $\mathrm{d}$ & 5,13 & & 19 & 5,13 \\
\hline & $\mathrm{e}$ & 2 & & 2 & 7,19 \\
\hline & $\mathrm{f}$ & 17 & & 17 & \\
\hline 2 & & 3,15 & 15 & 15 & 15 \\
\hline
\end{tabular}

${ }^{(1)}$ Genitores: 13: Vermelho 2157; 14: Ouro Negro; 15: Antióquia 8; 16: Ricopardo 896; 17: EMCAPA 404 - Serrano; 18 : Carioca; 19 : EMCAPA 405 Goytacazes; Combinações híbridas: 1: 13x17; 2: 14x17; 3: 15x17; 4: 16x17; 5: 13x18; 6: 14x18; 7: 15x18; 8: 16x18; 9: 13x19; 10: 14x19; 11: 15x19; 12: $16 \times 19$. 
e Argentina). Os outros genitores devem ter vindo para o Brasil pelas introduções de germoplasma da América Central (Gepts et al., 1986).

A importância relativa dos caracteres foi também avaliada visando identificar possíveis características dispensáveis. Conforme Cruz (1990), o grande interesse na avaliação da importância relativa dos caracteres reside na possibilidade de se descartarem características que contribuem pouco para a discriminação do material avaliado, reduzindo, dessa forma, mão-de-obra, tempo e custo despendidos na experimentação. Segundo Cruz \& Regazzi (1994), os caracteres dispensáveis em estudo de divergência genética compreendem os que são relativamente nãovariantes entre os indivíduos estudados, apresentam instabilidade com a mudança das condições ambientais

Tabela 5. Estimativas dos autovalores $\left(\lambda_{\mathrm{i}}\right)$, da variação acumulada $(\lambda \%)$ e da importância relativa das variáveis canônicas (VC) obtidas com base nas características florescimento (FLOR), maturação (MAT), número de vagens/parcela (NVP), número de sementes/vagem (NSV), peso de 100 sementes (PCS) e rendimento de grãos em kg/ha (RGH), avaliadas em 7 genitores e 12 combinações híbridas em $\mathrm{F}_{1}$ e $\mathrm{F}_{2}$, referente aos ensaios 1 e 2, respectivamente (1995).

\begin{tabular}{ccccrrrrrr}
\hline Ensaio & $\mathrm{VC}_{\mathrm{i}}$ & Variância & Variância & \multicolumn{7}{c}{ Importância relativa } \\
\cline { 5 - 9 } & & $\left(\lambda_{\mathrm{i}}\right)$ & acumulada $(\%)$ & FLOR & MAT & NVP & NSV & PCS & RGH \\
\hline 1 & $\mathrm{VC}_{1}$ & 6,631 & 56,091 & $-0,139$ & 0,109 & $-1,401$ & $-0,648$ & 0,653 & 1,409 \\
& $\mathrm{VC}_{2}$ & 2,534 & 77,526 & $-0,776$ & $-0,597$ & $-0,053$ & 0,427 & $-0,082$ & 0,584 \\
& $\mathrm{VC}_{3}$ & 1,856 & 93,228 & $-0,521$ & 0,148 & 0,937 & $-0,387$ & $-0,104$ & $-0,120$ \\
& $\mathrm{VC}_{4}$ & 0,436 & 97,924 & 0,498 & 0,218 & $-0,034$ & 0,252 & $-0,208$ & 0,639 \\
& $\mathrm{VC}_{5}$ & 0,241 & 98,964 & $-0,250$ & 0,808 & $-0,023$ & 0,289 & $-0,137$ & $-0,231$ \\
& $\mathrm{VC}_{6}$ & 0,122 & 100,000 & 0,158 & 0,167 & 0,760 & 0,705 & 0,763 & $-0,721$ \\
\hline \multirow{2}{*}{2} & $\mathrm{VC}_{1}$ & 12,343 & 59,750 & 0,210 & 0,081 & $-0,823$ & $-0,664$ & 0,772 & 0,403 \\
& $\mathrm{VC}_{2}$ & 5,055 & 84,224 & 0,707 & 0,310 & 0,143 & 0,009 & $-0,159$ & $-0,793$ \\
& $\mathrm{VC}_{3}$ & 2,022 & 94,013 & 0,392 & $-0,790$ & $-0,569$ & 0,441 & $-0,065$ & 0,584 \\
& $\mathrm{VC}_{4}$ & 0,831 & 98,040 & 0,574 & 0,116 & 0,761 & 0,088 & 0,124 & 0,099 \\
& $\mathrm{VC}_{5}$ & 0,304 & 99,514 & $-0,021$ & 0,352 & 0,551 & 0,963 & 0,437 & $-0,707$ \\
& $\mathrm{VC}_{6}$ & 0,100 & 100,000 & $-0,041$ & 0,613 & $-0,591$ & $-0,231$ & $-0,507$ & 0,763 \\
\hline
\end{tabular}

Tabela 6. Estimativas dos autovalores $\left(\lambda_{\mathrm{i}}\right)$, da variação acumulada $(\lambda \%)$ e da importância relativa das variáveis canônicas (VC) obtidas com base nas características emergência (EMERG), florescimento (FLOR), maturação (MAT), número de vagens/parcela (NVP), número de sementes/vagem (NSV), peso de 100 sementes (PCS) e rendimento de grãos em kg/ha (RGH), avaliadas em 7 genitores e 12 combinações híbridas em $F_{2}$ e $F_{3}$, referente aos ensaios 3 e 4 , respectivamente (1996).

\begin{tabular}{|c|c|c|c|c|c|c|c|c|c|c|}
\hline \multirow[t]{2}{*}{ Ensaio } & \multirow[t]{2}{*}{$\mathrm{VC}_{\mathrm{i}}$} & \multirow{2}{*}{$\begin{array}{c}\text { Variância } \\
\left(\lambda_{\mathrm{i}}\right)\end{array}$} & \multirow{2}{*}{$\begin{array}{c}\text { Variância } \\
\text { acumulada } \\
(\%)\end{array}$} & \multicolumn{7}{|c|}{ Importância relativa } \\
\hline & & & & EMERG & FLOR & MAT & NVP & NSV & PCS & RGH \\
\hline \multirow[t]{7}{*}{3} & $\mathrm{VC}_{1}$ & 25,286 & 64,710 & $-0,183$ & 0,205 & 0,639 & $-1,085$ & $-0,427$ & 0,660 & 0,576 \\
\hline & $\mathrm{VC}_{2}$ & 6,603 & 81,611 & 0,158 & 0,786 & 0,611 & 0,901 & 0,055 & $-0,473$ & $-0,925$ \\
\hline & $\mathrm{VC}_{3}$ & 3,729 & 91,155 & 1,048 & 0,176 & $-0,045$ & $-0,534$ & 0,182 & $-0,387$ & 0,573 \\
\hline & $\mathrm{VC}_{4}$ & 2,554 & 97,695 & $-0,097$ & 0,660 & $-0,446$ & $-0,714$ & 0,047 & $-0,062$ & 0,815 \\
\hline & $\mathrm{VC}_{5}$ & 0,483 & 98,931 & $-0,215$ & $-0,100$ & 0,425 & $-0,492$ & 0,342 & $-0,335$ & 0,822 \\
\hline & $\mathrm{VC}_{6}$ & 0,319 & 99,749 & 0,156 & 0,080 & $-0,051$ & 1,501 & 0,903 & 0,559 & $-0,814$ \\
\hline & $\mathrm{VC}_{7}$ & 0,097 & 100,000 & 0,242 & 0,120 & $-0,125$ & $-0,448$ & $-0,754$ & $-0,324$ & 1,189 \\
\hline \multirow[t]{7}{*}{4} & $\mathrm{VC}_{1}$ & 22,060 & 69,981 & 0,198 & 0,332 & 0,228 & $-0,608$ & $-0,524$ & 0,714 & 0,517 \\
\hline & $\mathrm{VC}_{2}$ & 4,267 & 83,519 & 0,481 & 0,875 & 0,323 & 0,096 & 0,019 & $-0,446$ & 0,060 \\
\hline & $\mathrm{VC}_{3}$ & 2,450 & 91,291 & $-0,100$ & $-0,455$ & 0,866 & 0,019 & $-0,147$ & $-0,214$ & $-0,063$ \\
\hline & $\mathrm{VC}_{4}$ & 1,395 & 95,719 & 0,758 & $-0,270$ & 0,130 & $-0,496$ & 0,240 & $-0,071$ & 0,285 \\
\hline & $\mathrm{VC}_{5}$ & 0,801 & 98,263 & 0,212 & 0,210 & $-0,037$ & 1,198 & 0,501 & 0,273 & $-0,189$ \\
\hline & $\mathrm{VC}_{6}$ & 0,456 & 99,710 & $-0,436$ & 0,105 & 0,337 & 0,428 & 1,097 & 0,369 & $-0,508$ \\
\hline & $\mathrm{VC}_{7}$ & 0,091 & 100,000 & $-0,195$ & 0,093 & $-0,037$ & $-0,742$ & $-0,347$ & $-0,326$ & 1,354 \\
\hline
\end{tabular}



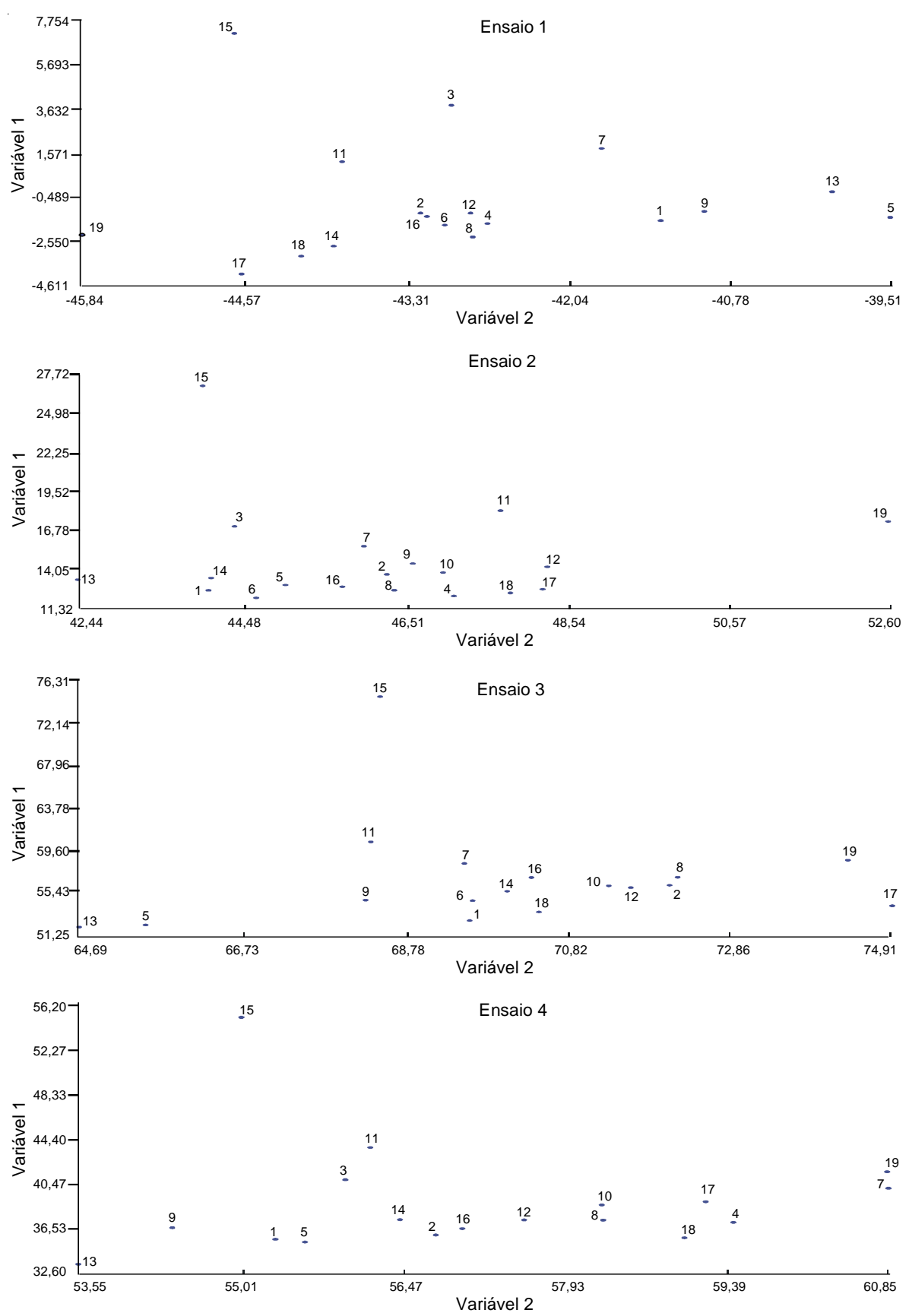

Figura 2. Dispersão gráfica de 7 genitores e 12 combinações híbridas de feijão em $\mathrm{F}_{1}$ e $\mathrm{F}_{2}$, referente aos ensaios 1 e 2 (1995), e $\mathrm{F}_{2}$ e $\mathrm{F}_{3}$, referente aos ensaios 3 e 4 (1996), respectivamente, em relação às duas primeiras variáveis canônicas. Genitores e combinações híbridas: 1: 13x17;

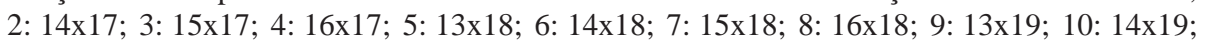
11: 15x19; 12: 16x19; 13: Vermelho 2157; 14: Ouro Negro; 15: Antióquia 8; 16: Ricopardo 896; 17: EMCAPA 404 - Serrano; 18: Carioca; 19: EMCAPA 405 - Goytacazes. 
ou são redundantes, por estarem correlacionados com outros caracteres. Assim, deve-se, também, analisar a matriz de correlação genotípica para auxiliar no descarte de características que são redundantes no estudo.

A importância relativa das características, na divergência genética dos germoplasmas, é quantificada pelos coeficientes de ponderação dos caracteres nas variáveis canônicas originais. No entanto, como os coeficientes são influenciados pela escala de avaliação das características, foi realizada a padronização desses coeficientes. Posteriormente, na avaliação da importância relativa dos caracteres na divergência genética, identificaram-se os de menor importância, entre os grupos de materiais, como sendo aqueles cujos coeficientes de ponderação, obtidos com a ponderação e padronização das variáveis, são de maior magnitude, em valor absoluto, nas últimas variáveis canônicas.

Os caracteres de menor importância, em ordem de descarte, foram: PCS, MAT, RGH, NVP e FLOR, no ensaio 1; RGH, NSV, NVPe MAT, no ensaio 2; RGH, NVP e EMERG, no ensaio 3; e RGH, NSV, NVP, EMERG, MAT e FLOR, no ensaio 4 (Tabelas 5 e 6). $\mathrm{Na}$ identificação das correlações genotípicas dessas características, considerando as estimativas de correlações genotípicas maiores de 0,7 (Ferrão, 1997), estas foram obtidas somente para as combinações FLOR e RGH (-0,711), no ensaio 1; NSV e MAT $(-0,917)$, no ensaio 2; EMERG e NVP (-0,723), no ensaio 3; e, NSV e MAT $(-0,775)$, no ensaio 4. Na análise conjunta dos quatro ensaios as características RGH e NVP foram as de menor importância no estudo de divergência genética. No entanto, como apresentaram baixa correlação genotípica com as demais características e são as de maior importância no processo produtivo, não devem ser descartadas.

$O$ fato de não terem sido identificados caracteres redundantes neste estudo está de acordo com o apresentado por Oliveira (1989) e Fonseca et al. (1995), que estudando 9 e 16 caracteres do feijoeiro, respectivamente, também não encontraram descritores redundantes.

\section{Conclusões}

1. Na análise genética dos genitores, as cultivares mais dissimilares são Antióquia 8, do grupo adaptado ao inverno, e EMCAPA 404 - Serrano, do grupo composto pelas variedades comerciais, e as cultivares mais similares são Ouro Negro e Ricopardo 896.
2. A divergência genética entre os genitores e as combinações híbridas é influenciada pela temperatura e pelo estádio de melhoramento.

\section{Referências}

CRUZ, C. D. Aplicações de algumas técnicas multivariadas no melhoramento de plantas. 1990. $188 \mathrm{f}$. Tese (Doutorado) - Escola Superior de Agricultura Luiz de Queiroz, Piracicaba.

CRUZ, C. D. Programa GENES: aplicativo computacional em genética e estatística. Viçosa, MG: Imprensa Universitária, 1997. $442 \mathrm{p}$.

CRUZ, C. D.; REGAZZI, A. J. Modelos biométricos aplicados ao melhoramento genético. Viçosa, MG: Imprensa Universitária, 1994.390 p.

DAVIS, J. R. C. Cluster analysis as an aid to selection for diversity in dry beans. Bean Improvement Cooperative Annual Report, East Lansing, v. 18, p. 21-23, 1975.

FALCONER, D. S. Introdução à genética quantitativa. Viçosa, MG: Imprensa Universitária, 1981. 279 p.

FERRÃO, M. A. G. Tolerância do feijão (Phaseolus vulgaris L.) ao frio: análise dialélica genética e correlação entre caracteres. 1997. 123 f. Tese (Doutorado) - Universidade Federal de Viçosa, Viçosa, MG.

FONSECA, R. J.; ANDRADE, M. J. B. de; FERREIRA, D. F. Divergência genética em germoplasma de feijão (Phaseolus vulgaris L.) coletado no sul de Minas Gerais. Ciência e Prática, Lavras, v. 19, p. 383-389, 1995.

GEPTS, P.; OSBORN, T. C.; RASHKA, K.; BLISS, F. A. Phaseolin protein variability in wild forms and landraces of the common bean (Phaseolus vulgaris): evidence for multiple centers of domestication. Economic Botany, New York, v. 40, p. 451-458, 1986.

OLIVEIRA, E. J. de. Análise multivariada no estudo da divergência genética entre cultivares de feijão (Phaseolus vulgaris L.). 1989. $71 \mathrm{f}$. Tese (Mestrado) - Universidade Federal de Viçosa, Viçosa, MG.

PETER, K. V.; RAY, B. Genetic divergence in tomato. Indian Journal of Genetics and Plant Breeding, Calcutta, v. 36, n. 3, p. 379-383, 1976.

RAO, R. C. Advanced statistical methods in biometric research. New York: J. Willey, 1952. 390 p.

SOARES, L. Melhoramento de batata-baroa (Arracacia xanthorrhiza Bancroft) II: divergência genética entre clones com base em procedimentos multivariados e estimativas de parâmetros genéticos. 1990. 85 f. Tese (Mestrado) - Universidade Federal de Viçosa, Viçosa, MG.

VIEIRA, C.; ARANTES, H. A. G; CRUZ, C. D.; ARAUJO, G. A. de. Triagem de germoplasma de feijão (Phaseolus vulgaris $\mathrm{L}$.) em busca de fontes de tolerância à baixa temperatura. Ciência e Prática, Lavras, v. 18, n. 3, p. 295-305, 1994. 